\title{
Trends in ICT and Multimedia Supported Education
}

\author{
Marko Papić, Janez Bešter \\ University of Ljubljana, Faculty of Electrical Engineering, Tržaška 25, 1000 Ljubljana, Slovenija, \\ marko.papic@Itfe.org, janez.bester@Itfe.org
}

The formal educational system is facing different problems regarding adaptation towards the needs of a modern knowledge society. In the article, two important and comprehensive challenges to today's formal educational system are discussed and commented upon. The first problem is the incoherence between the needs of the labor market and formal education system outcomes in terms of graduated students. Another problem is the distancing between the prevailing traditional pedagogical methods within formal educational institutions and the ways in which students acquire information and knowledge outside of the schools as they are becoming less and less interested in traditional lectures. It is argued that specific information and communication system technologies (ICT) supported mechanisms, such as social learning and virtual communities may address these challenges. Theories of communities and social learning that may be useful for implementation in the education system are explained and practical implementation is proposed.

Keywords: ICT supported education, social learning, virtual communities, credibility gap, multimedia education, e-learning

\section{Introduction}

The transition towards a post-industrial or knowledge-based society brought many changes in the daily lives of individuals, as well as organizations and corporate environments. These changes were rapid and accompanied by a large amount of information to be accepted, processed and understood. One of the areas affected by changes is education.

The authors of the article have already been contributing to the introduction of modern ICT into the formal education system of the Republic of Slovenia for more then ten years. Their e-learning system E-CHO (http://www.e-gradiva.si), along with multimedia courses are being used in elementary and secondary schools with more then 15000 regular users (teachers as well as students). The authors of the article are also studying the ongoing work of other projects and commercial providers in this field. In recent years there have been large financial investments, as well as organizational and implementation efforts of policy makers, experts and providers involved. However, when compared to the total number of students and learning practitioners, as well as to the variety of options provided by modern technologies, the success of introduction and use of ICT in schools in Slovenia are still not satisfactory. Students use ICT outside of schools to much greater extent then within the educational process. The majority of learning practitioners use ICT only to present their learning materials to students in a traditional way.
Based on the experience and an overview of the current situation, the authors identified two crucial challenges which have not yet been addressed, in order to increase the use of modern ICT in schools and to adapt the formal education system to the new era. The first challenge is to overcome the increasing credibility gap between the outcomes of the formal education system and expectations of the knowledge society employers. The second challenge is to adjust the knowledge transfer methods of the formal education systems to the most common information and knowledge acquisition manners of today's youth. Both challenges are addressed in this article. Possible solutions are provided, discussed and commented upon.

The hypothesis presented in the article is, that specific modern ICT concepts derived from virtual communities and social networks may couple the schools with the industry environment and bring the formal educational environment nearer to today's pupils and students without having to perform any complex structural changes to the education system itself.

\subsection{Formal educational system today and tomorrow}

The current formal educational system was first established in the mid $19^{\text {th }}$ century. As industrial society was under development, the system delivered only basic knowledge and 
skills. It was mostly oriented towards forming the working force. Knowledge needed at the work place included repetitive activities only and didn't change within the life time of an individual.

Since then, the basic concept of the formal educational system hasn't changed much. In the 20th century quantity of knowledge transferred from educational practitioners to learners expanded; however it was still designed according to the principle of "one size fits all". All learners were treated the same, given the same content and the same didactical methods.

Today we are becoming more and more aware that individuals have different talents, characters and different interests related to our work and education, yet the formal education system has not adapted. The formal curricula still mostly consists of repetitive knowledge/skills and does not adapt to the needs of the modern society, i.e. to the needs of the industry environment or take into account the future work places on any positions. Thus, the credibility gap is expanding as expectations and demands of the employers vary from the actual knowledge and skills acquired by current and future employees (Howie, 1996).

The credibility gap is occurring due to a lack of cooperation between the corporate environments and formal education system. The path towards the solution to this problem may be in establishing some sort of community between both environments. Communities can be formed in different manners, as explained in the later chapters of the article. ICT can foster creation as well as maintenance of such community.

The gap explained is not the only gap arising in recent years in the educational field. Existing and prevailing methods of knowledge transfer in formal educational institutions (a classical one way method - teacher to large group of students) are becoming more and more different from the informal methods of information and knowledge acquisition, most common to today's youth. As digital natives they live in the digital world from their birth, meaning that they use modern technologies to understand the world, communicate, play and learn, the same way older generations used pens and paper. Thus, they don't accept the knowledge gained from formal education the same way as they accept information from their daily lives. Modern ICT can answer this challenge as well, by means of social learning and the establishment of virtual communities.

\subsection{ICT and multimedia in education}

Until now, we have mentioned social learning and virtual communities as drivers of change in the formal education of the future. Both are thoroughly explained in the subsequent chapters of the article. There are also other ICT supported concepts that simplify and foster social learning, such as user-generated content and mobility.

Users with virtually no technical skills are able to produce rich multimedia digital content themselves. This puts them in the position of creators, unlike in the past, when they only accepted provided knowledge. Educators can become moderators or intermediaries instead of being the prevalent source of knowledge. Modern ICT therefore fosters learner-centered education with all its advantages.
Another evolutionary moment in education occurred with the appearance of simple to use, wide spread, powerful mobile ICT terminals, such as broadband connected tablet PC's or smart phones. These terminals gave mobility its real meaning as they replaced a variety of previously used devices and even school bags and provide high interactivity with peers, teachers or the digital content itself.

The described concepts of modern ICT are of crucial importance as they enable overcoming of past obstacles in order to introduce social learning into the formal education system.

\section{Methodology}

Tailored to the scope of the article, the methodology adopted seeks to address possible solutions to the presented problems of the formal education system through a bottom-up approach with the use of ICT. The bottom-up approach is the opposite of the analysis and proposal of structural changes in the formal education system, which is a set of complex, interdisciplinary tasks that should be coordinated by policy makers. The aim of the authors was for specific stakeholders, primarily learning practitioners and students, to embrace necessary changes in practice, during thelearning process itself, by means of modern ICT.

A multi source information gathering method was used in order to provide an initial robust solution that will cater to the stakeholders mentioned above and being able to satisfy their requirement as well as withstanding the test of time. The research sources are numerous and varied, in order to increase the information basis and diversify it. During preparation of the article, authors have carried out:

- Analysis of their own previous e-learning projects, pilot deliveries and implementations for elementary and secondary schools

- Formal and informal conversations, meetings and brainstorming with external experts and policy makers

- Desktop research and analysis of relevant literature on communities theory and social learning aspects.

- Initial design of the social learning management system, derived from the their own existing learning software E-CHO, which is already being used in elementary and secondary schools.

Findings from e-learning projects and implementations carried out in the past were used to define problems described in the introductory section of the article. Analysis of the relevant literature and desktop research was performed in order to clarify which conceptual types of the virtual communities existing in practice or theory would aid the establishment of social learning network and ties between the industry and formal education environments. The findings are presented in the following chapters about virtual communities and communities for management of knowledge.

Finally, the proposed solution is presented and discussed in the last chapters of the article. 


\section{Communities}

In the following chapter communities - as the most important mechanism to answer previously explained problems of the formal education system - are explained.

A community is a group of two or more people who have been able to accept and transcend their differences regardless of the diversity of their backgrounds (social, spiritual, educational, ethnic, economic, political, etc). This enables them to communicate effectively and openly and to work together toward goals identified as being for their common good (Hampton, 2005).

Generally, communities can be divided into seven typologies (Costa and Kahn, 2000):

- Practice communities

- Relations communities

- Learning communities

- Transaction communities

- Interest communities

- Fantasy communities

- Circumstance communities

In the following chapters we will focus on the types of communities which relate to educational activities. Mainly, these are communities of practice, which can be used to connect the corporate environment and formal educational institutions, as well as learning and interest communities.

\subsection{Practice communities}

Communities of practice are represented by a group of people who share a common interest and, through continuous interactions, solve problems relating to a common theme of interest, deepen their knowledge and experience (Wenger et al., 1999).

Communities of practice are social learning systems that combine individual learning and collective learning, where the contribution of the individual, in terms of creativity and experience, becomes part of the collective heritage of the community.

The shared knowledge is not static, but a repertoire of knowledge and knowledge subject to continuous revision based on the experience of individual members.

Communities of practice are the place where you activate the learning process, in which the generation of new knowledge is inseparable from practice (Sedita and Paiola, 2009).

Participants are often professionals and there are no hierarchical differences, but all are equally important because the work of each one is of benefit to the entire community (comsonet.org). With regards to employees' participation in communities of practice, it is important to attract as many people as possible because you can not know in advance who, within the community, may possess the knowledge that is needed at a given time (Ponassi, 2004).

Ponassi (2004) identifies two difficulties as regards practice communities.

The first is the resistance from the participants to share information and ideas in their possession. It may, in fact, develop forms of opportunistic behavior that exploits the com- munities without ever offering any help. A push for participation is given by:

- the intention to increase its visibility around the professional and create a positive image;

- an incentive system, e.g. establishing a prize for anyone who can give a valid contribution.

The second problem is the validation of the information found within the community of practice. The evaluation process is not generally based on criteria of response to objective truth, because the knowledge that communities elaborate is dynamic, emerging from constantly changing processes, and therefore does not allow definitive stabilization of the content to be discussed. A solution to this problem might be to nominate some people who are particularly aware and informed as leaders of each community of practice.

Wenger et al., (1999) define a community of practice as a combination of three fundamental elements:

- Domain, or thematic area, is the purpose for which a community exists, identifies the object around which the community is concentrated, creating a common ground and a sense of shared identity among members.

- Community creates the social fabric for learning. A strong community enables easier iterations at the base of the transmission of information and then knowledge.

- Practice is the specific knowledge the community develops, shares among members and keeps up-to-date with the evolution of techniques and knowledge.

Communities of practice can exist in different forms (Wenger, 2010):

Small or large. The small ones foster a feeling of familiarity and involve only a few specialists, while the large ones are made up of hundreds of people and are usually broken down by geographic region or joint issues in order to ensure that all members actively participate.

Long or short existence. Practice appears to be essential for the development of a community that has been stable for centuries thanks to the passage of knowledge from generation to generation (examples: the major automakers in Detroit, or the technology firms located in Silicon Valley). There are communities that might not last many years, because their presence is related to a project that when finished will cause the death of the community associated with it.

Within or distributed in space. One of the characteristics of a community is the continuous interaction between its members, for this reason communities usually begin among people working in or living near the same place who can easily interact. In any case, thanks to current technologies and Web 2.0, information sharing can also occur among people distant from each other, thus generating a very large community in terms of geographical areas.

Homogeneous or heterogeneous. Homogeneous communities are communities whose members have areas of common interest, they participate in the same discipline (woodworking, iron working, practice of the same sport, etc) or function (worker, manager, foreman, etc). On the other hand, heterogeneous communities rather bring together people with different backgrounds. 
Within or cross borders. Communities within borders are those that develop within the same company, department, or team. Communities that cross borders are those that affect multiple departments in the same company or several companies in the same organization, or even more different organizations.

Spontaneous or intentional. Many communities are born without intervention from an organization. In these cases, the participants spontaneously come together because they need each other as equals and partners in the learning process. In other cases, organizations have developed specific communities in order to manage the strategic areas of competence.

Another classification of communities of practice comes from (Pavlin 2006), in the article "Community of practice in a small research institute". In this classification, communities are:

\section{- Informal \\ - Structured \\ - Supported}

Informal communities are self-managed, as they do not have any organization that manages them, have a very large workforce and their training takes place in a natural way. There are discussion forums where creation and sharing of knowledge take place, which is then used by members in the workplace. Structured and supported communities instead develop under the attention of organizations, and community objectives are aligned with the objectives of the organization that manages and finances these communities.

\subsection{Learning communities}

Communities are involved in a learning experience and share a common path of discovery and growth (Scotti and Sica, 2007). People who are part of a learning community work, set themselves goals and divide tasks and responsibilitie in order to try to make a product or a common project.

Generally, learning communities have a boundary in time and space, linked to the end of the life span of the learning goal achievement (comsonet.org).

According to Briano et al., (1997) learning is a process by which we are enabled to belong to a community (e.g. at the end of university a student is able to work in the community of engineers). The membership about learning is also the ability to continue as part of the community in which our participation is recognized as a skill.

Learning communities are of particular interest in education today, as there has been a change in the concept of learning. It is no longer understood as a mere passive storage of contents, but with the aim to generate actions and solutions in various contexts in which the concepts are applied (Pozzi et al. 2007, Manca 2008).

\subsection{Interest communities}

Interest communities are places where people gather for the same interests, for the sheer purpose of sharing these inclina- tions and obtaining information with other not-for-purchase or other type (Ponassi, 2004).

People who are part of these communities have a shared interest or passion, like the fans of a football team, or fans of a band (comsonet.org).

\subsection{Circumstance communities/ Relation communities}

The community of circumstance unlike the community of practice, are not based on a shared interest, but their presence is based on circumstances and experiences, which have a strongly temporary character (Scotti and Sica 2007).

Typical examples are news groups that connect people with particular diseases, the passengers of an airplane, a ship or a train, which can be classified among the communities of circumstance (comsonet.org).

\subsection{Social networking}

Social networks are currently among the most popular phenomena of the Web (e.g. Msn.com, MySpace, Facebook, Orkut, etc). These are communities in which users, based on personal affinities or professional reasons, identify the people that can enter into a relationship, communicate, share information and digital content (Scotti and Sica 2007). These popular online tools have more then 800 million users worldwide and enable different types of interactions among users (Qualman, 2011. Social networks users tend to spend a lot of time online using social networks environment only. More then $50 \%$ of users use them on a daily basis and more then $20 \%$ spend more than a quarter of their time online within the most popular environments.

Social network concepts are important as they enable formal representation of social learning scenarios (Figure 1). Furthermore, social networks users are familiar with the concepts of social interactions. This means that no specific instructions are needed in order to perform the social learning activities.

\section{Communities for Knowledge Management}

The communities described so far are used for the management of knowledge (knowledge management).

From Figure 1 we can see how the community of practice in some way includes all other types of communities (the community of learning is also a community of practice, while the opposite is not always true). 


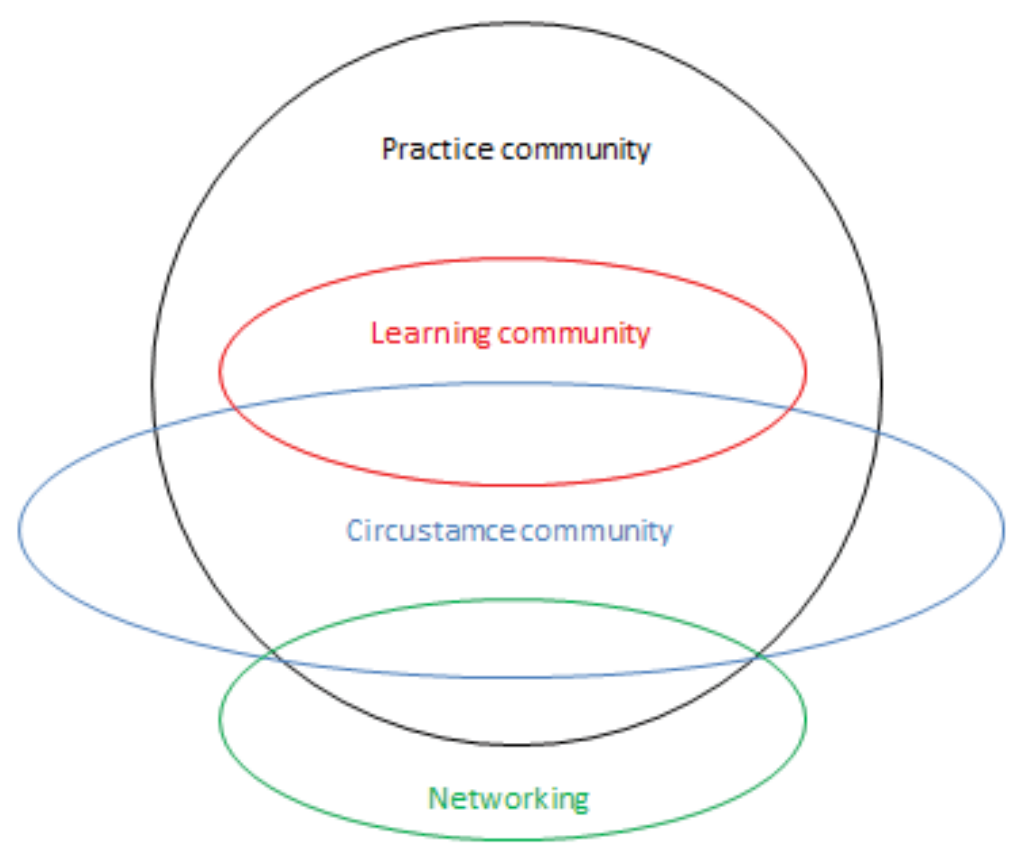

Figure 1. Communities for knowledge management (Sica and Scotti, 2007: 59)

\section{Implementation proposal in the formal education system}

From a functionalities point of view, the formal education system would require two types of communities. The community that connects the corporate environments field and educational institution would be predominantly a community of practice. The community to be used within the core of the education process would be a learning community.

In the implementation proposal, both communities are based on the existing Learning Management System (LMS) E-CHO, developed by the authors of the article. The reason for this is that LMS represent important mechanism in the ICT supported educational process. Commonly within the e-learning process, specific digital content has to be learned and understood or sets of activities have to be completed. LMS represent the environment to access the content and perform activities. Personalization features of LMS, along with the need to monitor the learning progress, remain important even in the social learning domain. The E-CHO LMS will therefore be upgraded to become a social learning environment.

Initial research and implementation in the field of so called Social LMS resulted in the delivery of several products, such as Knoodle (http://www.knoodle.com/), Topyx (http:// interactyx.com) and Sclipo (www.sclipo.com), all of which were launched in 2010. These systems are built from scratch, provide only simple LMS functionalities and are focused on a specific domain of use, such as innovative approaches to presenting multimedia content or simple social interactions (Figure 2a).

Another approach is to connect existing LMS to the most popular social networks such as Facebook (Figure 2b). For

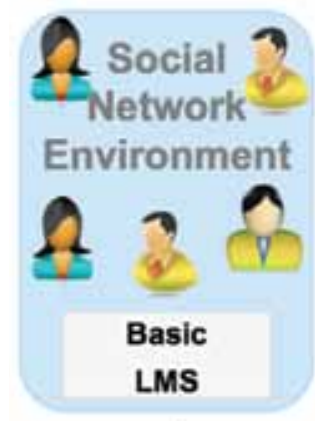

a.)
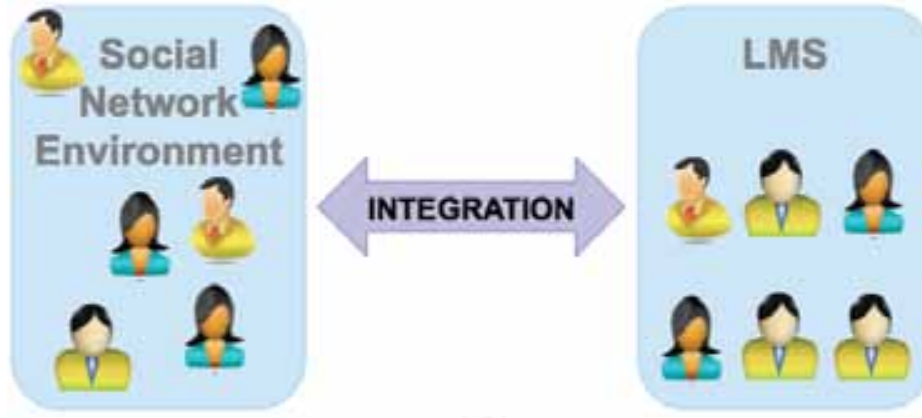

b.)

Figure 2. Existing social LMS scenarios: a.) Social Learning Platforms; b.) Integration of existing LMS with social network environment 
example, developers might launch an LMS as a Facebook application e.g. Udutu, Appfusion, E-CHO (Wing, 2011).. However, it is still not an ideal solution as the interactions occur either within the social network environment or LMS itself. A Facebook application can not provide all the LMS features necessary for the learning process entirely within the social network environment. Therefore, such initiatives usually result in the social network environment being another channel for delivering learning information or in some cases learning content.

LMS are generally systematically structured and rigid from the organizational point of view, as they reflect a formal educational environment. Students are organized into groups, depending on their age, school or class and have teachers tutoring them. The most popular social networks on the other hand tend to be established and self-organized by end users. Integration of both concepts, according to figure $2 \mathrm{~b}$ may result in a chaotic learning environment.

In the case of the E-CHO social learning environment implementation proposal, the concept, presented in Figure 2a will be used. The only difference is that the solution will not be developed from scratch, but will be based on existing cloud based LMS, which covers important e-learning areas of interest, such as content delivery, knowledge assessment, progress tracking, users and content management, and e-portfolios. Social interaction components are therefore being built over the existing LMS components.

Social learning functionalities will be provided to the users of E-CHO LMS as an added option. The students will be able to access their learning experience in two different ways. The traditional way of access is through standard E-CHO sections: the classroom, progress tracking, content development or user management sections. The new option will allow accessing through the E-CHO social learning environment.
Both access options will be equivalent in order to test whether the users will embrace the new social learning environment themselves. This community should be gradually introduced, because of the real threat of abuse and security risks of existing social communities.

Features that will distinguish this social learning environment from classical LMS can be divided into two main areas fostering social interaction:

- social collaboration features (including communication tools as well),

- features regarding motivation and incentives for participation in the learning process.

Social collaboration features will consist of:

- Chat service, interconnected with learning objects with integrated awareness of relations among users.

- Messaging, used for general communication and administrative purposes.

- Commenting - comments must be linked with learning objects encouraging users' communication focused on the target learning object.

- Recommending (rating) of learning objects.

- Posting different kinds of multimedia material (user statuses or learning objects)

- Sharing of learning materials or other multimedia objects generated during social learning experience.

- Buddies selected by users, as arbitrary peers in the learning process, independently of established organization within the E-CHO LMS.

The community of practice used to foster cooperation with industry will encompass end users directly. Participants and contributors of such communities will be:

- experts, employees from corporate environments,

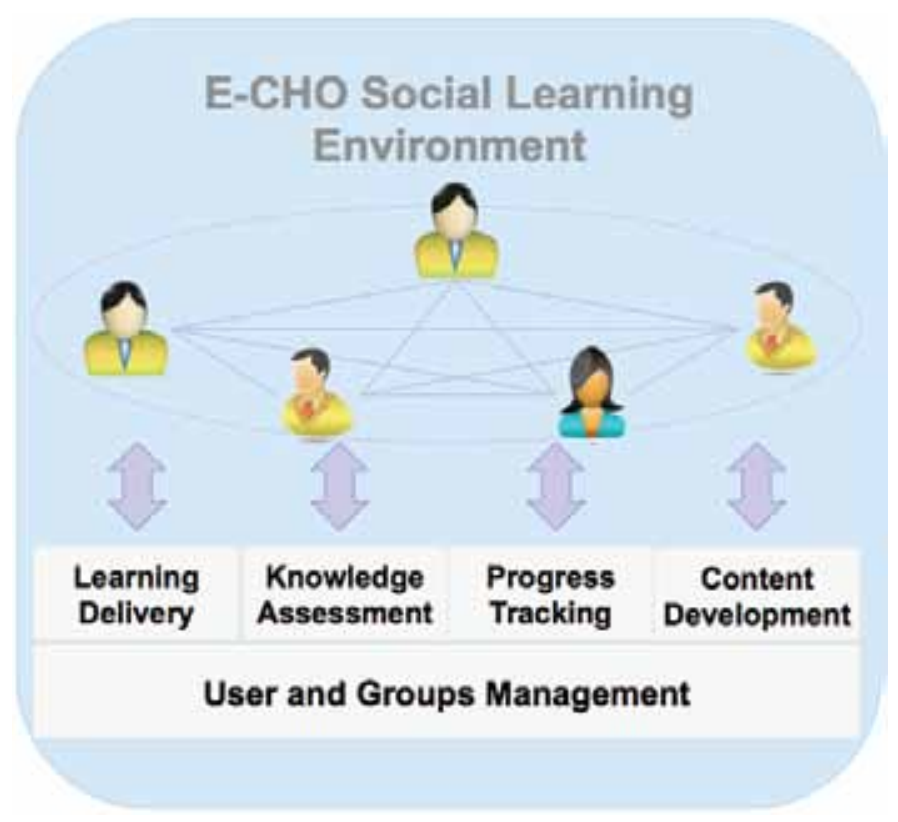

Figure 3: E-CHO Social Learning Environment implementation proposal 


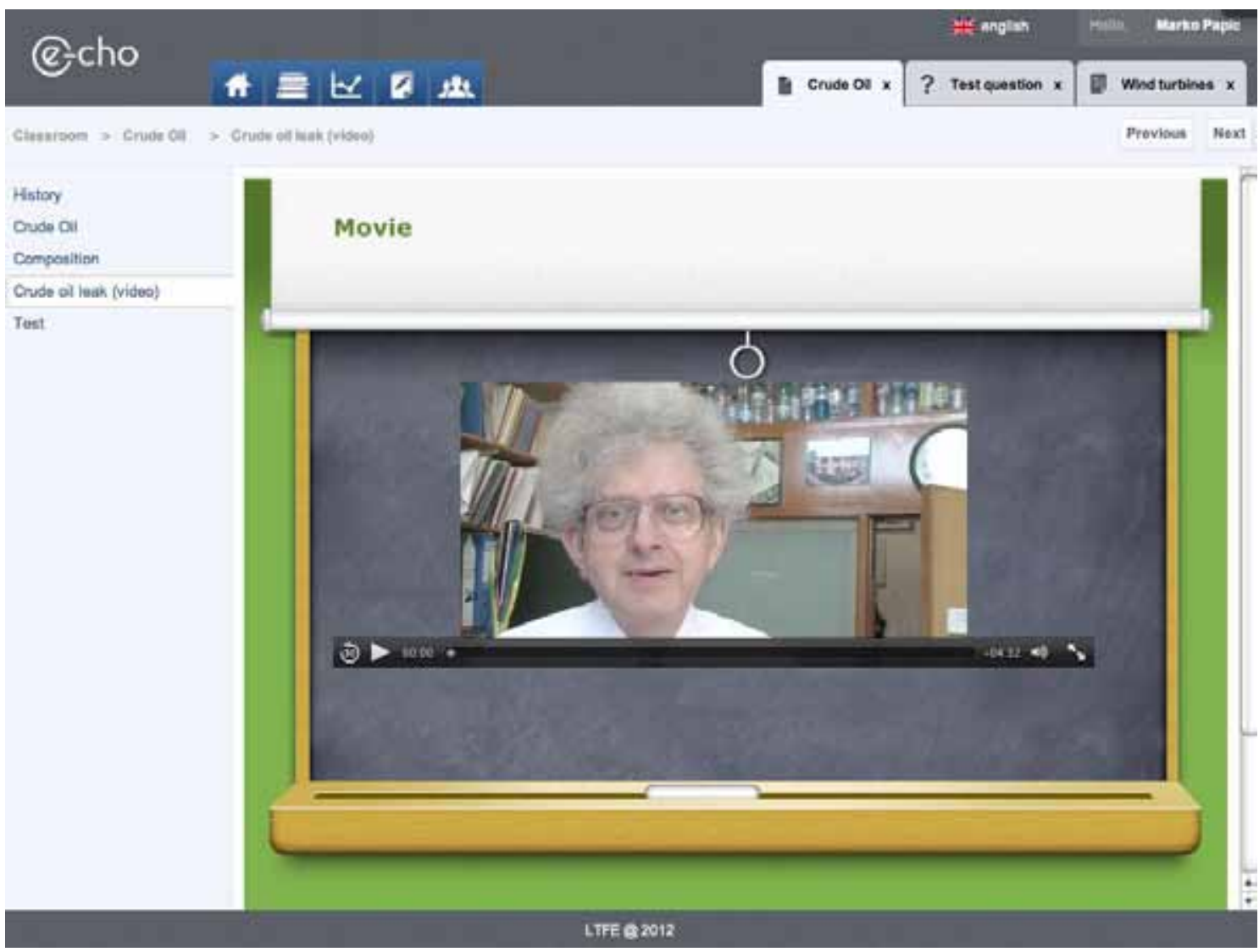

Figure 4: The E-CHO learning environment

- students, pupils from educational institutions and

- learning practitioners (teachers) as moderators.

The main aim of such a community will be for corporate environments to publish specific problems, related to their field of work and search for solutions from students and their teachers. These problems could be formed as minor projects, supported by documentation and other digital learning material (Tseng et al, 2006).

Such a community should have specific attributes, according to Wenger. It should be a large, heterogeneous community of long existence. Its establishment will of course be intentional. However, specific topics of interest will be spontaneous, on an as needed basis. Therefore it will combine features of communities of practice as well as circumstance communities.

Incentives for participation are especially important in the case of communities connecting the corporate environment and educational institutions. These will be derived from already implemented, commercially available, web-based collaboration platforms, such as Hypios (www.hypios.com) or Ponoko (www.ponoko.com). Related research was performed by various authors, such as Nof (2003) and Lakhani et al.,(2007). Motivation will incorporate intrinsic and extrinsic mechanisms. Extrinsic mechanisms are relatively easy to define. In the educational field active participation of students and learning practitioners will be acknowledged with rewards provided by participating corporate environments. By participating, students will collect reputation points, which could be then used to measure their activity or replaced for other benefits. Intrinsic motivation would come from students themselves. To achieve this, problems and projects originating from the corporate environment should be formed in a playing mode or competition mode. Intrinsic factors prove to be even more relevant then extrinsic factor in communities of practice (Venkatesh and Ramesh, 2006, Atanasijević-Kunc, et al., 2011).

Motivation for participation of corporate environments would be completely different. Their main interest would be to identify potential future human resources and to follow them with relatively little time consuming effort (Baba et al, 2009).

\section{Discussion}

The gap between students and the formal education system is increasing, due mainly to the prevalence of classical lecturing methods at a time when students work with information and knowledge in a completely different manner. Changes to education system will have to occur, not because of ICT, but in order to increase the active participation of students in the learning process. 
Modern ICT may provide an answer to this problem, as well as to the rising of credibility gap, however it is yet to be seen whether the adoption of new technologies, as explained in the article, would be sufficient for the formal education system to better encompass labor market needs.

Both communities will have to be gradually introduced as the social learning community brings the threat of abuse and certain questions will have to be answered. What is the most appropriate age at which students should begin using such communities? What will the boundaries of such communities be and how will they be managed at a high level? Providing and assuring privacy or intellectual property rights is a challenge even for the largest and most developed popular communities at present. In the case of the formal education environment, the target group is sensitive and management (control) will have to be provided. After initial testing on a limited group of users, the social learning environment will gradually be added to students and teachers already using the E-CHO e-learning LMS. Analysis of their use will be performed in order to gather enough information to perform further user experience testing and analysis.

Based on previous experience of introducing e-learning (as ICT based education) supported by LMS, digital content and variety of ICT tools, the desired changes within the formal educational system will not happen instantly. Existing ICT in education, introduced since the beginning of Internet, did not bring about desired changes and did not revolutionize the system as many anticipated.

In order to address the challenges of formal education systems, ICT can represent a path towards the solution and bring about initial success, however, complex structural and institutional changes will be required, independently of the introduction of ICT in the educational system.

\section{References}

Atanasijević-Kunc, M., Logar V., Karba R., Papić M. \& Kos A. (2011): Remote Multivariable Control Design Using a Competition Game. IEEE Transactions on Education 54(1): 97-103, DOI: 10.1109/TE.2019.2046489

Baba, Y., Shichijo, N. \& Sedita, S.R. (2009). How do collaborations with universities affect firms' innovative performance? The role of "Pasteur scientists" in the advanced materials field. Research Policy, 38(5): 756-764, DOI: 10.1016/j.respol.2009.01.006

Briano R., Midoro V. \& Trentin G. (1997); Computer Mediated Communication and Online Teacher Training in Environmental Education; Journal of Information Technology for Teacher Education, 6(2): 127-146, DOI: 10.1080/14759399700200012

Costa D. L. \& Kahn, M.E. (2003). Civic Engagement and Community Heterogeneity: An Economist's Perspective. Perspectives on Politics, 1(1): 103-111, DOI: 10.1017\%2FS1537592703000082

Hampton J. (2010). Group Dynamics and community building. Retrieved December 18, 2011, from http://www.community4me.com/

Howie J. G. (1996). Addressing the credibility gap in general practice research: better theory; more feeling; less strategy, $\mathrm{Br} J$ Gen Pract., 46(409): 479-481.

Lagace, M. (2006). Open Source Science: A New Model for Innovation, Working Knowledge, Harvard Business School, Copyright 2007, Retrieved January 19, 2012, from http://hbswk. hbs.edu/item/5544.html
Lakhani, K. R., Jeppesen, L.B., Lohse P.A \& Panetta, J. A. (2007). The Value of Openness in Scientific Problem Solving, Working Knowledge, Harvard Business School. Retrieved January 19, 2012, from http://hbswk.hbs.edu/item/5612.html

Manca S. (2008). Computer-mediated Communication Learning Environments: The Social Dimension. In A. Cartelli \& M. Palma (Eds), Encyclopedia of Information Communication Technology (vol. 1, pp. 121-126). IGI Global. DOI: 10.4018/978-1-59904845-1

Nof, S. Y. (2003). Design of Effective e-Work: Review of Models, Tools, and Emerging Challenges. Production Planning and Control, 15(8): 681-703, DOI: 10.1080/09537280310001647832

Qualman, E. (2011). Social network users statistics. Socialonomics, Retrieved January 19, 2012 from http://www.socialnomics. net/2011/08/16/social-network-users-statistics/

Paiola M. \& Sedita S.R. (2009). Il Management Della Creativita. Reti, comunit e territori. Milan, Italy, Carocci.

Pavlin, S. (2006). Community of practice in a small research institute. Journal of Knowledge Management, 10(4): 136-144. DOI: 10.1108/13673270610679426

Ponassi, F. (2004): Communita Virtuali e Piccole Medie Imprese, Milan, Italy, FrancoAngeli.

Pozzi, F., Manca, S., Persico, D. \& Sarti, L. (2007). A general framework for tracking and analysing learning processes in CSCL environments. Innovations in Education \& Teaching International, 44(2): 169-179. DOI: 10.1080/14703290701240929

Scotti E. \& Sica R. (2007). Community Management, Milan, Italy, Apogeo-Feltrinelli.

Tseng K. C. \& Abdalla, H. (2006). A novel approach to collaborative product design and development environment. Proceedings of the Institution of Mechanical Engineers, Part B: Journal of Engineering Manufacture, 220: 1997-2020, DOI: 10.1243/09544054JEM485

UDUTU (2008). UdutuTeach \& Udutu Learn: Facebook Plugin., January 19, 2012, from: http://www.udutu.com/solutions_udututeach_udutulearn.html

Venkatesh V. \& Ramesh V. (2006). Web and Wireless Site Usability: Understanding Differences and Modeling Use. MIS Quarterly, 30(1): 181-206.

Wenger E. (2010). Communities of Practice and Social Learning Systems: the Career of a Concept. In: C. Blackmore (Ed.). Social Learning Systems and Communities of Practice, Part III, Springer, pp. 179-198, DOI: 10.1007/978-1-84996-133-2_11

Wenger E. (1999). Communities of practice: the key to a knowledge strategy. Knowledge Directions, Volume 1, Number 2, pp. 48-63, DOI: 10.1016\%2FB978-0-7506-7293-1.50004-4

Wing T. (2011). AppFusion: Facebook - The Social LMS Benchmark, Learning Solutions Magazine. Retrieved January 14, 2012 from http://www.learningsolutionsmag.com/articles/764/appfusionfacebook--the-social-lms-benchmark

Marko Papić received a B.Sc. and M.Sc. degree from the Faculty of Electrical Engineering, University of Ljubljana, Slovenia, in 2000 and 2003 respectively. He has collaborated at the Laboratory for Telecommunications within Faculty of Electrical Engineering since 1998. His pedagogical, research and development activities are focused on the field of telecommunication systems and services. He is interested in design and implementation of Internet and mobile applications, services and solutions. His main fields of research are e-learning services and content development. He is the author of several papers, which have been presented in national and international telecommunications conferences. 
Janez Bešter, Ph.D., is a Professor at and the Head of the Laboratory for Telecommunications at the Faculty of Electrical Engineering, University of Ljubljana, Slovenia. His work focuses on the planning, realization and management of telecommunication systems and services, implementation and application of information technologies into education, and economic opportunities for knowledge-based societies. With over 25 years of experience he is a member of several national councils and committees. He leads different national and international projects, bridging the gap between industrial development and academic research. Efficient knowledge transfer through cooperation with different enterprises, institutions and individual experts is among his main goals. 